\title{
Optimal management of scapholunate ligament injuries
}

This article was published in the following Dove Press journal:

Orthopedic Research and Reviews

\section{Geoffrey Konopka' \\ Harvey Chim ${ }^{2}$}

'Department of Orthopaedic Surgery, McGovern Medical School, University of Texas Health Science Center, Houston, TX, USA; ' Division of Plastic and Reconstructive Surgery, University of Florida College of Medicine, Gainesville, FL, USA
Correspondence: Geoffrey Konopka Department of Orthopaedic Surgery, University of Texas Health Science

Center - Houston,6400 Fannin St, Suite

1700, Houston, TX 77030, USA

$\mathrm{Tel}+\mathrm{I} 3017758190$

Fax + I 8882790074

Email drkonopka@gmail.com

Harvey Chim

Division of Plastic and Reconstructive Surgery, University of Florida College of Medicine, 1600 S.W. Archer Rd, Gainesville, FL 32608, USA

Tel +l 3522738670

Fax + I 3522738639

Email harveychim@yahoo.com
Abstract: Scapholunate ligament (SLL) injuries are a common cause of wrist pain and instability. Treatment of SLL injuries requires intricate understanding of wrist anatomy and biomechanics. Mindful physical exam and appropriate diagnostic studies can orient the surgeon to the defined stage of injury. Review of the literature on each treatment by stage can prepare the upper extremity surgeon to provide the best evidence-based care. The optimal management of SLL injuries should result in a stable, painless wrist.

Keywords: scapholunate ligament, wrist instability, wrist trauma, carpal dissociation, carpal instability, SLAC wrist

\section{Introduction}

The wrist has a complex ligamentous anatomy. When the wrist anatomy is disrupted, the biomechanics are altered and the result can be painful and destabilizing. Injury to the scapholunate ligament (SLL), in particular, is a common and well-researched topic. We will review the anatomy of this injury, the resulting pathologic biomechanics, and address the diagnosis, staging, and treatment of SLL injuries.

\section{Anatomy and biomechanics}

The ligamentous anatomy of the carpus is complex (Figure 1). There are extracapsular ligaments and intracapsular ligaments. There are three extracapsular ligaments: the transverse carpal ligament, and the ligaments that connect the pisiform to the hook of the hamate, and the base of the fifth metacarpal. The intracapsular ligaments can be categorized as extrinsic or intrinsic. The extrinsic ligaments originate at the radius or ulna and insert on the carpus. The intrinsic ligaments both originate and insert on the carpus. While the extrinsic ligaments typically have midsubstance ruptures, the intrinsic ligaments often avulse from the cartilage of the carpal bone. ${ }^{1}$ There are seven volar extrinsic ligaments of the wrist: radioscaphoid, radioscaphocapitate, long radiolunate, short radiolunate, ulnocapitate, ulnotriquetral, and ulnolunate. ${ }^{1,2}$ There is one dorsal extrinsic ligament of the wrist: the dorsal radiotriquetral. ${ }^{2}$

The intrinsic ligaments of the wrist are those ligaments between the carpal bones. In the proximal row, the scapholunate and the lunotriquetral joints each have a complex of transverse ligaments; a palmar ligament, a dorsal ligament, and a proximal fibrocartilaginous membrane. The dorsal SLL is the strongest in the scapholunate joint whereas the palmar lunotriquetral ligament is the strongest in the lunotriquetral joint. ${ }^{2}$ The scaphoid spans both the proximal and distal rows, and links movement between the 
rows through the scaphocapitate and scaphotrapeziotrapezoid ligaments. There are also palmar and dorsal midcarpal ligaments as seen in Figure 1. Of special interest to scapholunate stability, the dorsal intercarpal ligament spans the dorsum of the carpus from the triquetrum over the distal aspect of the proximal row to the scaphoid, trapezoid, and trapezium.

The stability of the wrist is dependent on the anatomy and the dynamic biomechanics of the wrist. The scaphoid has a shorter radius of curvature at its base than the lunate, which results in a greater range of motion for the scaphoid at the radiocarpal joint than the lunate. The scaphoid flexes almost twice as much as the lunate in the sagittal plane at the radiocarpal joint. ${ }^{3}$ The lunate has a larger base palmarly than dorsally, resulting in a tendency for the lunate to assume an extended position. ${ }^{4}$ Due to the oblique orientation of the scaphoid to the longitudinal axis, radial deviation of the carpus at the radiocarpal joint results in flexion of the scaphoid as it articulates with the radius, and ulnar deviation of the carpus results in extension of the scaphoid. ${ }^{3}$ Through the scapholunate joint, the lunate will flex and extend passively with the scaphoid, but to a lesser degree. The unique shape and orientation of the scaphoid and the radioscaphoid articulation allow a unique motion that has been called the "dart-thrower's motion". 5 This motion occurs when the hand moves from an extended and radially deviated position to the flexed and ulnarly deviated position, as when a person throws a dart. This motion is very common in activities of daily living. ${ }^{6}$ The radially deviated position of the hand results in a flexion moment on the scaphoid, but the extended position of the wrist results in an extension moment on the scaphoid.
A

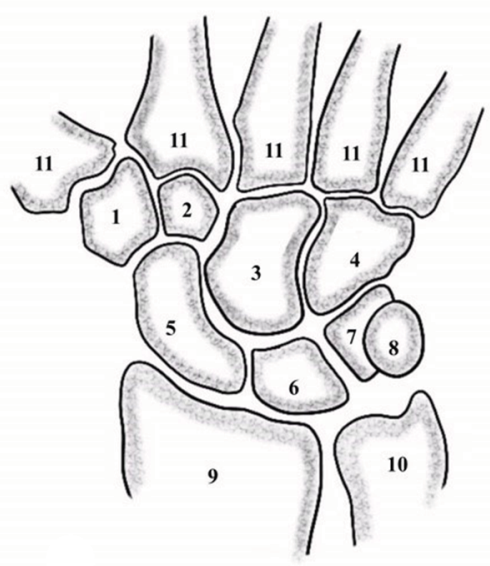

C

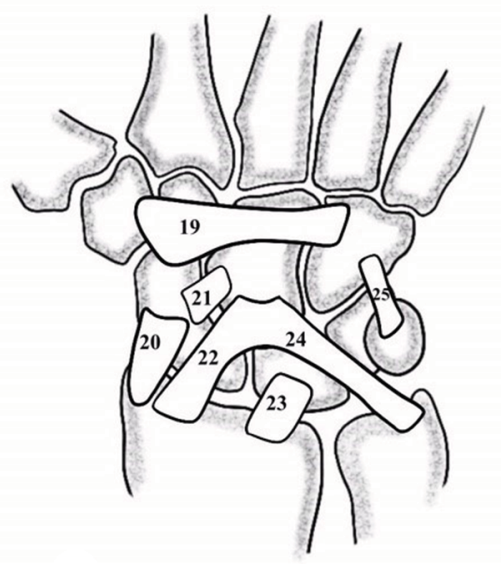

B

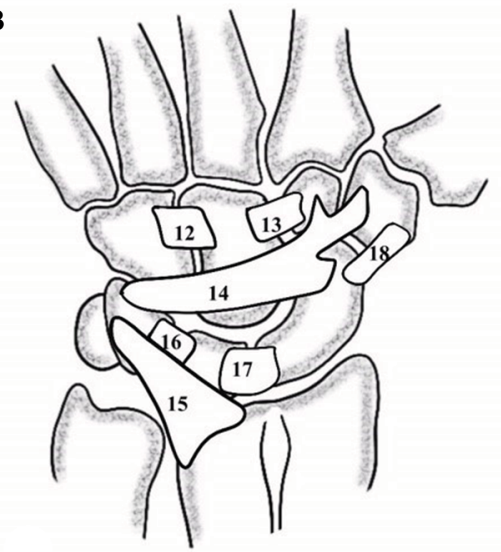

D

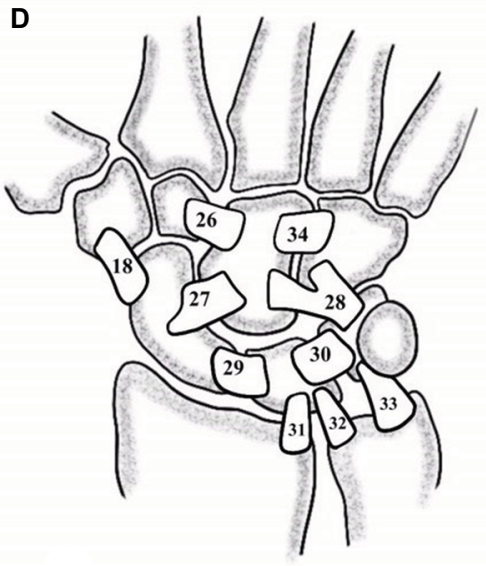

Figure I Wrist anatomy.

Notes: (A) The bones of the wrist: trapezium (1), trapezoid (2), capitate (3), hamate (4), scaphoid (5), lunate (6), triquetrum (7), pisiform (8), radius (9), ulna (10), and the bases of the metacarpals (II). (B) The dorsal wrist ligaments: dorsalcapitohamate (12), dorsal capitotrapezoid (13), dorsal intercarpal ligament (14), radiotriquetral (15), dorsal lunotriquetral (16), dorsal scapholunate (17), and dorsolateralscaphotrapeziotrapezoid (18). (C) The palmar superficial wrist ligaments: transverse carpal ligament (19), radioscaphoid (20), scaphocapitate (21), radioscaphocapitate (22), long radiolunate (23), ulnocapitate (24), and pisohamate (25). (D) The palmar deep wrist ligaments: palmar capitotrapezoid (26), scaphocapitate (27), triquetral-hamate-capitate (28), palmar scapholunate (29), palmar lunotriquetral (30), short radiolunate (3I), ulnolunate (32), ulnotriquetral (33), and palmar capitohamate (34). 
In a healthy wrist, the scaphoid will therefore remain neutral, and the lunate follows. Along the dart-thrower's motion, the scaphoid and lunate remain neutral. At the end of the motion, the wrist is flexed, which places a flexion moment on the scaphoid, but the ulnar deviation places an extension moment on the scaphoid. The majority of the dart-thrower's motion occurs through the midcarpal joint and places significant strain across the scapholunate joint. ${ }^{7}$

Normal physiologic loads transmit large forces across the wrist joint. ${ }^{89}$ While the carpal bones in the distal row of the carpus distribute axial loads relatively evenly, $50 \%$ of an axial load through the wrist is transmitted through the radioscaphoid joint and $35 \%$ across the radiolunate joint. ${ }^{8,9}$ As the SLL is between these two primary load-sustaining bones, it is easy to understand how a destabilizing injury can occur here. In a normal joint, even under large physiologic loads, the carpal bones will displace only a very small amount, and they will keep their positional relationships to each other. The scapholunate interosseous ligaments are not the only ligaments maintaining scapholunate alignment. The secondary stabilizers of the scapholunate joint are the scaphotrapeziotrapezoid, scaphocapitate, radioscaphocapitate, and dorsal intercarpal ligaments. ${ }^{10}$ The dorsal intercarpal ligament lends a strong secondary restraint to the scapholunate joint. In cadaveric studies where the entire SLL and volar ligaments were sectioned, the scapholunate joint did not show diastasis or excessive scaphoid flexion. However, once the dorsal intercarpal ligament was sectioned, scapholunate instability was noted. ${ }^{11,12}$ Further research on the ligamentous stability of the dorsal wrist has investigated the role of the dorsal capsule-scapholunate septum (DCSS). The DCSS is a ligamentous connection between the dorsal capsule of the wrist to the SLL and the dorsal intercarpal ligament. ${ }^{13}$ It has been demonstrated in cadaveric studies to play some role in the stability of the scapholunate joint as sectioning of the DCSS results in increased scapholunate instability. ${ }^{14,15}$

Secondary dynamic stabilizers play a role in the stability of the scapholunate joint. Isometric contraction of abductor pollicis longus, extensor carpi radialis longus (ECRL), and flexor carpi ulnaris induced midcarpal supination. Midcarpal supination tightens the volar scaphoid-distal row of the carpus, lending stability to the scaphoid. ${ }^{16}$ The flexor carpi radialis (FCR), in particular, rotates the scaphoid into flexion and supination when loaded, and pronates the capitate and triquetrum. Both of these actions contribute dynamic stability to the carpus. ${ }^{17,18}$ Proprioception and neuromuscular control also play a role in the stability of the scapholunate joint, in particular. Afferent information is collected at the ligaments of the wrist when stretched, and results in reflex motor control stabilizing the wrist joint via the secondary muscular stabilizers. ${ }^{19,20}$ In-vivo studies using electromyography have shown that denervation of the anterior or posterior interosseous nerves can lead to dysfunction of the stabilizing reflex pathways of the wrist joint. ${ }^{21,22}$

If the anatomy of the proximal carpal row is disrupted and the secondary stabilizers fail, an axial load will cause the scaphoid to flex and pronate, while the lunate and triquetrum will extend and supinate. ${ }^{4}$ Carpal instability results in abnormal pressure on the cartilage of the wrist, which can result in arthritis. ${ }^{2,23}$ SLL injuries are the most common cause of carpal instability. ${ }^{24}$

\section{Scapholunate ligament injury}

SLL injuries resulting in scapholunate dissociation are thought to occur most commonly following a fall onto an extended, ulnarly deviated wrist. The position that a hand assumes holding a steering wheel has also been postulated as a possible predisposition for an SLL injury during a motor vehicle accident. ${ }^{25}$ Dissociation of the scapholunate joint is the most frequent carpal instability. ${ }^{26}$ About $13.4 \%$ of distal radius fractures are associated with scapholunate dissociation. ${ }^{27}$ Mayfield et al described scapholunate dissociation as the first stage of a predictable four-stage pattern of perilunate instability. ${ }^{28}$ An extension and supination force will pull the scaphoid by the scaphotrapezoid-capitate ligaments, and the lunate will be unable to follow into extension due to the radiolunate and ulnolunate ligaments. If the force is great enough, the scapholunate interosseous ligaments rupture from palmar to dorsal. Continued force application can progress to a perilunate dislocation. Once the SLL is incompetent, the scaphoid flexes and displaces dorsally, and the lunate extends. This position of malalignment allows for abnormal cartilage contact pressures, which lead to a progressive pattern of wrist arthritis namely scapholunate advanced collapse (SLAC). ${ }^{24,29}$ Not all SLL injuries result in SLAC or perilunate dislocation. Carpal instability can also result from chronic conditions such as rheumatoid arthritis, pseudogout, and Kienböcks disease through attritional rupture. ${ }^{30}$

Watson et al described a spectrum of injury resulting from rotary subluxation of the scaphoid. ${ }^{31}$ Using static and dynamic radiographs, the injuries can be categorized into four groups: predynamic instability, dynamic instability, static scapholunate dissociation, and SLAC (Table 1). In predynamic instability, radiographs do not reveal malalignment. In dynamic instability the scapholunate interval may widen under a clenched-fist radiograph or live fluoroscopy with a 
Table I Spectrum of scapholunate instability by radiograph

\begin{tabular}{ll}
\hline Group & Description \\
\hline $\begin{array}{l}\text { Predynamic } \\
\text { instability }\end{array}$ & $\begin{array}{l}\text { Radiographs do not reveal injury but physical exam } \\
\text { is positive for pain with wrist use }\end{array}$ \\
$\begin{array}{l}\text { Dynamic } \\
\text { Radiographs will reveal the injury under stressed or } \\
\text { Static }\end{array}$ & $\begin{array}{l}\text { dynamic loading } \\
\text { scapholunate }\end{array}$ \\
$\begin{array}{l}\text { dissociation } \\
\text { Scapholunate }\end{array}$ & without stressed or dynamic loading \\
advanced collapse & with arthritic changes at the wrist \\
\hline
\end{tabular}

Note: Data from Watson et al. ${ }^{31}$

range of motion or loading of the wrist. The secondary stabilizers of the scapholunate joint maintain the scapholunate alignment when no stress is applied. In static scapholunate dissociation, the injury is evident on plain radiographs. The SLL is completely torn and malalignment exists. A final group of instability, SLAC, can be seen when the scaphoid is displaced and there is evidence of arthritis. ${ }^{29}$ SLAC has its own spectrum based on the progression of arthritis. In the first stage, arthritic changes begin at the radial styloid. In the second stage, the arthritic changes progress to the radioscaphoid joint. In the third stage, arthritic changes are evident at the capitolunate joint. In the fourth stage there is evidence of arthritis throughout the radiocarpal and midcarpal joints.

\section{Diagnosis of scapholunate ligament injury}

SLL injuries often result in decreased grip strength, swelling, and tenderness over the dorsoradial aspect of the wrist. ${ }^{26}$ Abnormal movement of the scaphoid can result in a clicking or clunking sensation in the wrist. However, the presentation may not be typical. The physician should obtain a detailed account of the patient's injury. Pain must be elucidated for location, duration, severity, character, and any previous treatments. Medical and surgical history may yield the causation of the wrist pain or contributing factors. Lifestyle and handedness can help determine and tailor the treatment. A focused physical exam of the wrist begins with observation of the external appearance of the wrist and hand. Signs of trauma may be evident. Palpation of the wrist anatomic landmarks may elicit informative tenderness. There may be pain in the anatomic snuffbox or the palmar scaphoid tuberosity. The Watson scaphoid shift test can help identify the injury. ${ }^{31}$ This test is done by stabilizing the scaphoid with one hand while using the other hand to move the wrist from ulnar to radial inclination. When the wrist is ulnar, the scaphoid is extended, and as the wrist is brought radial, the scaphoid flexes. If the SLL is incompetent, the proximal pole of the scaphoid will displace dorsally in radial inclination until pressure is relieved, then the scaphoid reduces, and this shift is palpable. Neurovascular examination is important to determine not only injuries to the neurovascular structures but also the possibility of an acute carpal tunnel syndrome, which can occur after acute wrist trauma. ${ }^{32}$ Range of motion of the wrist should be measured and compared to the contralateral limb. Grip strength should be compared between extremities. A good physical exam does not only help determine if there is an SLL injury, but can help determine if intervention is needed. If imaging has already been performed and is suggestive of injury, but the exam is completely benign, there may be no need for further treatment. Watson et al found that in their study of 1,000 individuals, $21 \%$ had normal hypermobility in one of their scaphoids. ${ }^{31}$

Imaging of the wrist should begin with plain radiographs. Well-performed radiographs will help the physician determine if there is malalignment of the carpal bones. There are four views that should be obtained initially: posteroanterior (PA), lateral, scaphoid projection, and oblique view. A healthy wrist in an appropriately performed PA view will show smooth, continuous curved lines at the proximal aspect of the distal carpal row, the distal aspect of the proximal carpal row, and the proximal aspect of the proximal carpal row. These lines were described by Linn et al and can be used to assess carpal malalignment. ${ }^{33}$ Disruption of these normally smooth lines occurs when malalignment is present (Figure 2). Contralateral films are necessary for comparison. An additional view that may be beneficial in evaluating scapholunate injury is the anteroposterior wrist view with the fist clenched. This view is obtained similar to the PA view but with the wrist held fully supinated on the film, and the hand is pulled into a fist. Clenching the fist will load the carpus and can widen the diastasis of the scapholunate joint if there is a dynamic instability. A dynamic PA radiograph of the wrist moving from radial to ulnar deviation may show unequal spacing between the carpal bones, such as increased diastasis of the scapholunate with ulnar deviation. These views can also be done under a live scan, or cineradiography, to show the movement of the carpus with stressing. Dynamic cineradiography can be a useful tool for evaluating scapholunate injury with a high sensitivity and specificity. ${ }^{34}$

Once imaging has been obtained for a wrist with suspected scapholunate injury, there are key characteristics to look for. On the PA view, diastasis $\geq 3 \mathrm{~mm}$ between scaphoid and lunate can indicate pathology, but is not specific for injury. ${ }^{35}$ Scapholunate diastasis seen on the PA has been called 
the "Terry Thomas sign" after an English comedian with a significant diastema between his front teeth (Figure 3). ${ }^{26,36}$ Another radiologic finding, the "scaphoid ring sign", can sometimes be seen on the PA when the scaphoid flexes abnormally, and the scaphoid is imaged down its long axis, creating the appearance of a ring. ${ }^{35}$ Both the Terry Thomas sign and scaphoid ring sign can be seen in wrists without a history of trauma. Comparison of the contralateral wrist

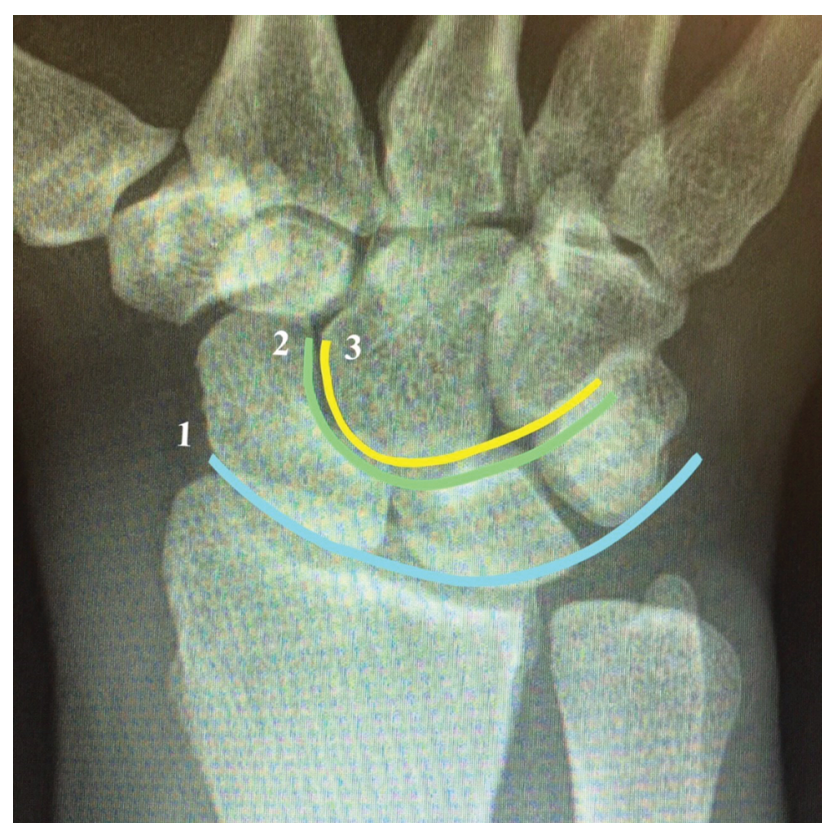

Figure 2 Uninterrupted “Gilula Lines” I, 2, and 3 in a wrist with normal alignment.

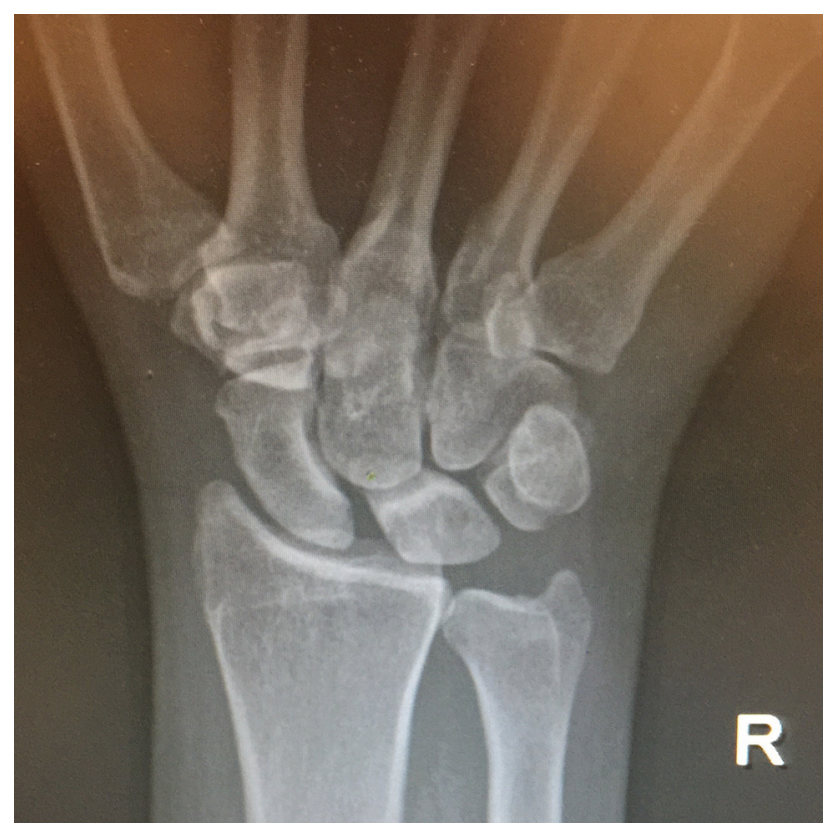

Figure 3 "Terry Thomas" sign on a wrist PA radiograph showing scapholunate diastasis. imaging and clinical correlation can confirm the diagnosis of pathology. The lateral view of the wrist can help determine if the scapholunate injury has resulted in instability. On the lateral view of the wrist, the scaphoid and lunate have a typical appearance, in which their longitudinal axes form an angle between $30^{\circ}$ and $60^{\circ} \cdot{ }^{24,35}$ When the scaphoid and lunate lose their normal relationship in an SLL injury, the scaphoid flexes and the lunate extends, resulting in a scapholunate (SL) angle $>60^{\circ}$ (Figure 4). This is called dorsal intercalated segment instability (DISI). ${ }^{24}$

Computed tomography (CT) scanning is a useful modality for imaging wrist pathology. For the wrist, it is best to obtain CT imaging along the axis of the scaphoid, and it is best to obtain 1-2 mm intervals in axial, sagittal, and coronal planes with 3D reconstruction. CT scanning can help visualize fractures as well as the geometric relationships of the carpal bones to each other. Magnetic resonance imaging (MRI) has also proven very useful in the diagnosis of SLL injuries. ${ }^{37,38}$ When obtaining a wrist MRI, the patient should be prone, with their hand over their head and the wrist held in a neutral position. The wrist should be imaged in the conventional three planes in 1-2 mm intervals, and it is best to use a $3 \mathrm{~T}$ magnet. ${ }^{38}$ With a good MRI, the fibers of the scapholunate can be seen as well as malalignment of the carpal bones. Minimal dorsal subluxation of the scaphoid in comparison to

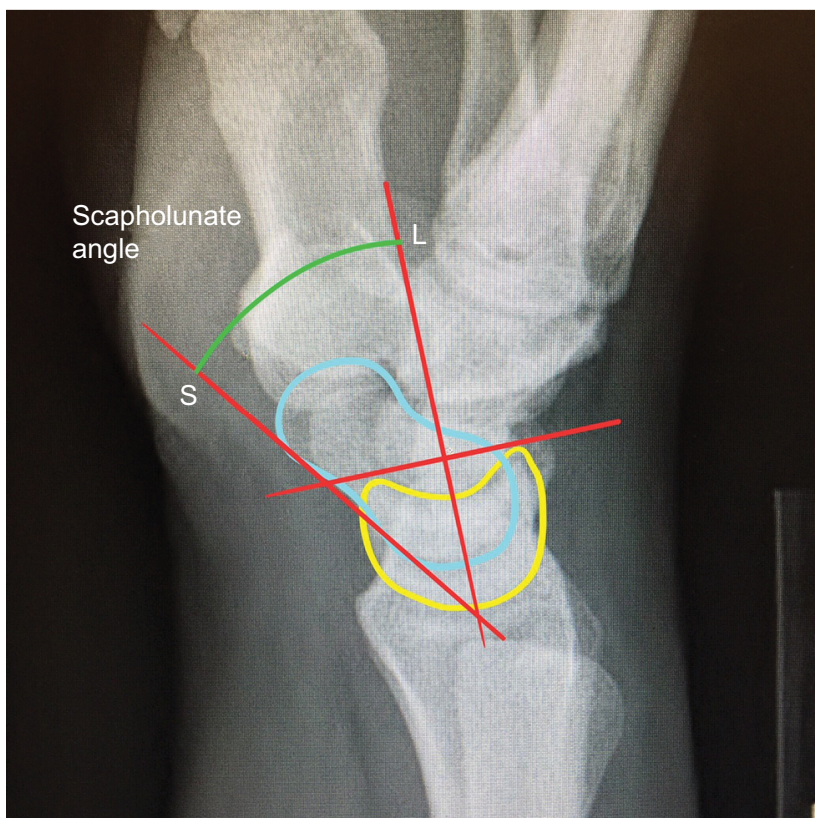

Figure 4 The scapholunate angle is measured on a lateral radiograph of the wrist. Notes: The scaphoid line $(S)$ is drawn tangential to the scaphoid along the palmar aspects of the distal and proximal poles of the bone. The lunate line $(L)$ is drawn perpendicular to a line drawn tangential to the palmar and dorsal points of the lunate. The scapholunate angle is measured between the two lines. 
the radial scaphoid fossa of $10 \%$ on a wrist MRI has a $72 \%$ sensitivity of scapholunate interosseous ligament injury with a specificity of $100 \% .{ }^{37}$

\section{Treatment of scapholunate ligament injuries}

Wrist arthroscopy has been an essential tool for the assessment and treatment of SLL injuries. ${ }^{39-42}$ When wrist arthroscopy is performed for instability, it is important to perform both radiocarpal and midcarpal arthroscopy. Geissler et al developed an arthroscopic-based grading system for carpal interosseous tears (Table 2). ${ }^{42}$ There has been evolution of the arthroscopic classification of SLL injuries. Dreant and Dautel expanded on the use of a probe during wrist arthroscopy to determine the staging of the injury. ${ }^{43,44}$ The European Wrist Arthroscopy Society developed a more comprehensive classification that includes the site of the SLL injury. A stage I injury allows no passage of the probe. A stage II lesion involves the membranous SLL. A grade III A lesion is a partial injury of the volar SLL and results in volar widening on dynamic testing from the midcarpal joint. A grade III $\mathrm{B}$ lesion is a partial injury of the dorsal SLL and results in dorsal widening of the scapholunate joint on dynamic testing. A grade III C lesion is a complete tear of the SLL with reducible widening of the scapholunate space with removal of the probe. A grade IV lesion is a complete scapholunate injury with passage of the arthroscope possible from the midcarpal to the radiocarpal joint. A grade $\mathrm{V}$ lesion is a wide scapholunate diastasis, which allows passage of the arthroscope through the scapholunate joint and is seen on static radiograph to show an increased gap and DISI deformity. ${ }^{45}$ Dynamic testing can be performed during arthroscopy to

Table 2 Geissler arthroscopic classification of intracarpal ligament tears

\begin{tabular}{ll}
\hline Grade & Description \\
\hline I & $\begin{array}{l}\text { Hemorrhage and attenuation of the interosseous ligament } \\
\text { viewed from the radiocarpal joint and no step-off at the } \\
\text { midcarpal joint } \\
\text { Hemorrhage and attenuation of the interosseous ligament at } \\
\text { the radiocarpal joint; there is step-off viewed at the midcarpal } \\
\text { joint and the probe can be placed between the scaphoid and } \\
\text { lunate } \\
\text { Step-off between the scaphoid and lunate is viewed at both } \\
\text { the radiocarpal and midcarpal joints, and the probe can be } \\
\text { easily placed and rotated between the scaphoid and lunate } \\
\text { Gross instability is noted at the scapholunate interval and } \\
\text { a 2.7-mm arthroscope can be placed in the scapholunate } \\
\text { diastasis }\end{array}$ \\
IV $\quad$
\end{tabular}

Note: Data from Geissler et al. ${ }^{42}$ further evaluate the severity of injury, which may not show on imaging. Combined injuries to the scapholunate and lunotriquetral ligaments can be found on arthroscopy using the "rocking chair sign" in which the lunate can rock volar and dorsal with the probe when it normally should exhibit no rocking. ${ }^{46}$ The scaphoid "3D" test or scaphoid dorsal dynamic displacement test can be performed arthroscopically to evaluate scapholunate instability if the scaphoid shifts dorsally with regard to the lunate upon pressure at the scaphoid tubercle. ${ }^{47}$ Arthroscopy can also be useful for the treatment of some SLL injuries, but not all SLL injuries are best treated with arthroscopy. Determining which SLL injuries require nonoperative management, arthroscopy, or open surgery has been a contested and heavily researched topic.

The spectrum of SLL injury is large, with ongoing discussion of the best treatments, and insufficient evidence to declare gold standards. The general treatment categories include nonoperative management, acute scapholunate repair, scapholunate reconstruction, intercarpal fusions, salvage procedures, and wrist arthrodesis. In addition to the staging systems defined by Watson et al and Geissler et al, Garcia-Elias et al described another staging system that can be used to guide SLL injury treatment as well (Table 3). ${ }^{31,42,48}$ The first stage is incomplete SLL injury. The second stage is complete SLL injury with repairable SLL. The third stage is complete, irreparable SLL injury with normal alignment. The fourth stage is complete SLL injury, irreparable ligament, and reducible rotary subluxation of the scaphoid. The fifth stage is complete SLL injury with irreducible malalignment but normal cartilage. The sixth and final stage is complete SLL injury with irreducible malalignment and cartilage degeneration. Each stage has treatment options tailored to the injury.

\section{Stage I: incomplete SLL injury}

In stage 1 SLL injuries, the ligament is only partially ruptured. The patient may complain of pain when lifting objects or placing an axial load on the wrist. There is no diastasis on standard or stress views between the scaphoid and lunate, which also categorizes these injuries as predynamic instability. Pain may be the result of inflamed synovium and abnormal cartilage contact pressures. These injuries can correspond to Geissler grade I-III. The recommended treatment for stage 1 SLL injuries is arthroscopy. With arthroscopy, the pathology can be visualized, and the synovium and nonviable tissue can be debrided. Case series studies have shown arthroscopic debridement of stage 1 SLL injuries to provide symptomatic relief in the majority of patients. ${ }^{49,50}$ Electrothermal shrinkage has also been used for stage 1 SLL injuries with limited but 
Table 3 Treatment of scapholunate dissociation by stage

\begin{tabular}{|c|c|c|}
\hline Stage & Description & Treatments \\
\hline $\mathrm{I}$ & Incomplete SLL injury & Arthroscopic debridement and electrothermal shrinkage \\
\hline 2 & Complete, repairable SLL injury & Open repair of SLL with K-wire stabilization \\
\hline 3 & $\begin{array}{l}\text { Complete, irreparable SLL injury with normal } \\
\text { alignment }\end{array}$ & $\begin{array}{l}\text { Dorsal capsulodesis (Blatt) } \\
\text { Ligamentoplasties: } \\
\text { Mayo Clinic SL ligamentoplasty } \\
\text { Dorsal intercarpal ligamentoplasty } \\
\text { Bone-ligament-bone reconstruction } \\
\text { Dynadesis dynamic ECRL tendon transfer }\end{array}$ \\
\hline 4 & $\begin{array}{l}\text { Complete, irreparable SLL injury with reducible } \\
\text { malalignment }\end{array}$ & $\begin{array}{l}\text { SL ligamentoplasty with tendon graft: } \\
\text { Brunelli and Brunelli, three-ligament tenodesis } \\
\text { Garcia-Elias modification } \\
\text { Ross modification } \\
\text { Corella modification } \\
\text { Spiral tenodesis } \\
\text { Reduction-association of the scapholunate }\end{array}$ \\
\hline 5 & $\begin{array}{l}\text { Complete SLL injury with irreducible malalignment, } \\
\text { normal joint cartilage }\end{array}$ & $\begin{array}{l}\text { Partial fusions: } \\
\text { Scaphoid-trapezium-trapezoid arthrodesis } \\
\text { Scapholunate arthrodesis } \\
\text { Scaphoid-capitate arthrodesis } \\
\text { Scaphoid-lunate-capitate arthrodesis } \\
\text { Radioscaphoid-lunate arthrodesis and distal } \\
\text { scaphoidectomy }\end{array}$ \\
\hline 6 & $\begin{array}{l}\text { Complete SLL injury with irreducible malalignment } \\
\text { and cartilage damage }\end{array}$ & $\begin{array}{l}\text { Radial styloidectomy } \\
\text { Scaphoidectomy and midcarpal fusion } \\
\text { Proximal row carpectomy } \\
\text { Total wrist arthrodesis }\end{array}$ \\
\hline
\end{tabular}

Note: Data from Garcia-Elias et al. ${ }^{48}$

Abbreviations: ECRL, extensor carpi radialis longus; SL, scapholunate; SLL, scapholunate ligament.

positive results. Darlis et al used arthroscopic debridement and electrothermal shrinkage in stage 1 SLL injuries and reported 14 out of 16 patients having pain relief and a grip strength average of $78 \%$ of the contralateral limb. ${ }^{51}$ Percutaneous pinning with arthroscopic or fluoroscopic guidance has been used in the treatment of stage 1 SLL injuries although there is no strong evidence to support this treatment. ${ }^{52}$

\section{Stage 2: complete, repairable dorsal SLL injury}

In stage 2 SLL injuries, the ligament is completely ruptured but the dorsal SLL ligament is repairable. These injuries may show diastasis of the scapholunate joint on stress radiographs, revealing dynamic instability. ${ }^{31}$ The dorsal SLL is usually repairable up to 1 month after the injury when the ligament still has a healing potential and is sufficiently strong enough to hold a repair. ${ }^{52-54}$ The SLL can avulse from the scaphoid, the lunate, have a midsubstance rupture or have a partial rupture with elongation, but the most common form of rupture is avulsion from the scaphoid. ${ }^{55}$ The recommended treatment for stage 2 SLL injuries is open reduction, dorsal SLL repair, and internal fixation. This technique is performed through a dorsal midline approach to the wrist. A skin incision is made longitudinally just ulnar to Lister's tubercle. The extensor retinaculum is divided over the third dorsal compartment and the extensor pollicis longus is displaced radially. The retinacular flaps are developed radially and ulnarly. The ligament-sparing capsulotomy described by Berger et al can be performed to access the scapholunate joint. ${ }^{56}$ The capsule is incised just distal to the radius from the radial styloid along the dorsal edge of the radius to the center of the origin of the radiotriquetral ligament. The incision is then angled toward the triquetrum within the radiotriquetral ligament. The incision is then carried back to the radial side of the wrist splitting the fibers of the dorsal intercarpal ligament. The carpus can then be inspected. If the scaphoid and lunate are not in their normal intercalated position, Kirschner wires (K-wires) can be used to "joystick" the bones to their appropriate positions. The scaphoid should be directed proximal and ulnar while the lunate should be directed distal and radial to correct the typical injury deformity. The SLL can be repaired with suture anchors or with transosseous sutures. ${ }^{54,57}$ Two or more 1.2$\mathrm{mm} \mathrm{K}$-wires can then be inserted percutaneously across the SL and scaphocapitate (SC) joints to protect the SLL repair. 
When placing the K-wires, a small incision should be made just distal to the radial styloid, and blunt dissection utilized to avoid damaging the dorsal sensory branch of the radial nerve. The K-wires can be removed at 8-10 weeks. The wrist should be immobilized for these 8 weeks and then protected for an additional 4 weeks from weight bearing, in a removable splint. Range of motion exercises for the fingers should begin as soon as possible. Range of motion exercises and strengthening of the wrist can begin at 12 weeks. Arthroscopic techniques for both volar and dorsal SLL suture repairs have been developed to address SLL injuries that do not need full reconstruction and can save the patient large incisions and disruption to the soft tissue. ${ }^{58-60}$ A retrospective review of SLL repairs showed acute repairs performed better than chronic repairs with lower failure rates. Patients with worker's compensation status were found to have an increased rate of surgical repair failure. ${ }^{61}$ There is, however, insufficient evidence that stage 2 SLL repairs will halt the progress of SLAC.

\section{Stage 3: complete, irreparable SLL injury with normal alignment}

In stage 3 SLL injuries, the ligament is completely ruptured and irreparable. Like stage 2 SLL injuries, diastasis of the scapholunate joint may be present on stress radiographs, revealing dynamic instability. ${ }^{31}$ The patient may report feeling clunking or weakness when lifting or loading the wrist. The SLL may have degenerated after a midsubstance tear, or the injury may be chronic and the SLL no longer has the healing potential. ${ }^{55}$ Unlike stage 2 SLL injuries, because the SLL is irreparable, stability must be restored with more than simple repair and protection. Most treatments for restoring stability in stage 3 SLL utilize local tissue to supplement the secondary stabilizers. These tissues have included the capsule, the intrinsic ligaments, the extrinsic ligaments, tendons, and bone-ligament-bone autograft. ${ }^{62-67}$ The dorsal capsulodesis was designed to help correct the flexion and pronation that the scaphoid assumes after an SLL injury. The Blatt technique for dorsal capsulodesis is performed by tethering the scaphoid with a portion of the radioscaphoid capsule in order to hold the scaphoid extended. ${ }^{68}$ A proximally based capsular flap is created and inserted into the neck of the scaphoid after the alignment has been corrected and protected with K-wires. The original technique used sutures through the scaphoid and over a button on the palmar thenar skin. The capsulodesis is then protected in a thumb spica cast for 8 weeks and the K-wires are removed at 12 weeks. Range of motion exercises are started afterward. The "Mayo Clinic scapholunate ligamentoplasty" uses a portion of the dorsal intercarpal ligament instead of the capsule. Half of the dorsal intercarpal ligament is released from the triquetrum and inserted onto the lunate to create an additional scapholunate constraint. ${ }^{24}$ Szabo et al described the "dorsal intercarpal ligamentoplasty", in which the scaphoid origin of the dorsal intercarpal ligament is reinserted at a more radial position on the scaphoid neck to correct abnormal pronation of the scaphoid. ${ }^{63,66}$ Retrospective reviews of the Blatt capsulodesis have shown improvements in symptoms for some patients, but also significant decreases in range of motion and strength as well as no significant improvement in carpal alignment or prevention of arthritis. ${ }^{67-69}$ Similarly, the "dorsal intercarpal ligamentoplasty" and the "Mayo Clinic scapholunate ligamentoplasty" have also shown decreased range of motion and grip strength with no evidence of preventing future wrist arthritis. ${ }^{63,66,70}$

SLL reconstruction has also been attempted with free, untethered bone-ligament-bone autografts. ${ }^{64,71}$ One method utilizes bone-retinaculum-bone autograft from the distal radius at Lister's tubercle. ${ }^{71}$ Another method uses a portion of the third metacarpal-capitate dorsal ligament to reconstruct the SLL. ${ }^{64}$ The bone portions of these grafts are impacted and fixed with wire or screws into the scaphoid and lunate with the theory that the reconstruction will be stronger and have better healing potential than capsule or previously attempted soft tissue ligamentoplasties. There is little long-term evidence on bone-ligament-bone reconstructions, but these techniques have also been shown to have limited effect on preserving carpal alignment and preventing wrist arthritis. ${ }^{71}$

Another method to treat dynamic SLL injuries described by Seradge et al utilizes the FCR and ECRL tendons to actively constrain the scaphoid. ${ }^{72} \mathrm{~A}$ two-third thickness segment of the ECRL is passed through a drill hole in the distal pole of the reduced scaphoid and tenodesed palmarly to the FCR tendon. The ECRL is then a dynamic extensor of the scaphoid, the FCR is a static tether, and this construct theoretically prevents abnormal flexion of the scaphoid. Seradge et al report positive results at 5 years in a cohort of 102 patients with pain relief in 94\%, grip strength increased an average of $65 \%$, active wrist range of motion increased by $9 \%$, and good to excellent results in $85 \%$ of the patients. ${ }^{72}$

\section{Stage 4: complete, irreparable SLL injury with reducible malalignment}

In stage 4 SLL injuries, the ligament is irreparable and there is carpal malalignment at rest. Arthroscopy will reveal no cartilage damage in stage 4 SLL injuries. These wrists exhibit static instability. ${ }^{31}$ The scaphoid will assume a flexed 
and pronated position, and the lunate will be in an extended position. Plain radiographs will show fixed SL diastasis on the PA view and an increased SL angle on the lateral view. If the long and short palmar radiolunate ligaments are intact, the lunate will not show ulnar displacement and the malalignment will be easily reducible. ${ }^{48}$ The patient will commonly report clunking or weakness when lifting or loading the wrist. When the radiolunate ligaments are intact, the main treatment options in stage 4 SLL injuries include reconstruction of the SLL with tendon grafts or creation of a fibrous nonunion at the scapholunate joint with the reduction-association of the scapholunate (RASL) procedure. ${ }^{48,73,74}$ When the scapholunate joint has lost the primary and secondary stabilizers, more robust tissue is needed to support the SLL reconstruction than local ligament or capsule. The ECRL has been used previously to reconstruct the SLL through large tunnels in the scaphoid and lunate, with high rates of bone fracture and arthritis progression. ${ }^{36}$ Brunelli and Brunelli described an SLL reconstruction technique in which both the primary and secondary stabilizers would be strengthened. ${ }^{74}$ The Brunelli and Brunelli scaphotrapezoid tenodesis is performed by dividing the FCR tendon proximally, maintaining the insertion at the base of the second metacarpal, then threading the tendon from the scaphoid tuberosity palmarly to the neck of the scaphoid dorsally, then inserting the tendon into the dorsal radius at the origin of the dorsal radiocarpal ligament. Brunelli and Brunelli reported significant symptomatic relief in all their patients and maintenance of the reduction at latest follow-up. ${ }^{74}$ Garcia-Elias et al modified this technique into the "three-ligament tenodesis". ${ }^{48}$ The procedure is performed by dividing the FCR tendon proximally, maintaining the insertion at the base of the second metacarpal, then threading the tendon obliquely from the palmar aspect of the scaphoid tuberosity to the dorsum of the scaphoid at the origin of the dorsal SLL, then across the SL joint and fixed to the dorsum of the lunate with suture anchor. The remainder of the FCR tendon is pulled through a hole made in the radiotriquetral ligament and sutured back onto the lunate portion of the tendon. K-wires are placed across the SL and SC joints to protect the reconstruction. The wrist is protected in a thumb spica cast for 6 weeks and then in a removable splint for an additional 6 weeks. The K-wires are removed at 8 weeks postoperatively. Garcia et al reviewed the treatment in 38 patients with an average follow-up of 46 months and found pain was relieved in 28, grip strength was an average of $65 \%$ compared with the contralateral side, flexion and extension range of motion was at $74 \%$ and $77 \%$, respectively, compared with the contralateral, and recurrence of carpal malalignment in two wrists. Arthritic changes were seen in seven wrists. ${ }^{48}$ The Ross modification of the three-ligament tenodesis brings the FCR tendon through transosseous tunnels in the scaphoid, lunate, and triquetrum and fixes the tendon into the triquetrum with an interference screw. The remainder of the tendon is then secured to the dorsal intercarpal ligament. ${ }^{75}$ Ross et al reported good short-term radiographic and clinical results in 40 patients at 12 months of follow-up. ${ }^{75}$

A study performed by De Smet et al on patients who underwent the three-ligament tenodesis for SLL injury found that preexisting arthritic changes and poor scapholunate reductions resulted in poor outcomes. ${ }^{76}$ Poor scapholunate reductions may have been the result of unidentified radiocarpal instability. In some stage 4 SLL injuries, the lunate will displace ulnarly due to injury to the radiolunate ligaments. This instability pattern has been described by Taleisnik as an SL instability with ulnar translation. ${ }^{77}$ Taleisnik "type 2" SL injuries, which have ulnar translation, need more stabilization than the three-ligament tenodesis. Chee et al developed a modified technique of the three-ligament tenodesis to address radiocarpal instability called the "antipronation spiral tenodesis". ${ }^{78}$ The procedure is performed similar to the three-ligament tenodesis with the FCR tendon tunneled through the scaphoid, brought dorsally across the lunate, and then brought from the dorsum of the triquetrum to the palmar aspect of the triquetrum through an interosseous tunnel and finally inserted into the radial styloid. Long-term evidence is needed to support the efficacy of the spiral tenodesis, but the procedure theoretically recreates more stabilizing vectors than previous tendon grafting techniques.

Arthroscopic scapholunate ligamentoplasties have been described, combining the advantages of arthroscopic techniques and open techniques. Corella et al modified the three-ligament tenodesis to be performed arthroscopically. ${ }^{79}$ The FCR tendon is brought through a transosseous tunnel in the scaphoid dorsally, then through a transosseous tunnel in the lunate from dorsal to palmar, and the tendon is fixed in place at each tunnel with interference screws. The remainder of the tendon is sutured to the volar surface of the scaphoid. Corella et al have also described an arthroscopic approach to reconstruct both the volar and dorsal SLLs with a minimally invasive technique. ${ }^{80,81}$ A clinical cohort study performed by Ho et al on an arthroscopic ligamentoplasty reconstructing the volar and dorsal SLLs followed its patients for an average of 48.3 months and found improvements in pain score, wrist motion, and grip strength. ${ }^{82}$

Overall, tendon reconstructions for SLL injuries have had mixed results in terms of reduction maintenance and 
prevention of arthritis. ${ }^{36,76}$ The mixed results of SLL reconstruction with tendon grafting may be the result of the material: tendon graft may not be durable enough to withstand the repetitive physiological loads placed on the wrist. Scapholunate arthrodesis has been used to create a more stable proximal carpal row after SLL injury, at the expense of normal carpal kinematics and wrist range of motion. ${ }^{83-87}$ Scapholunate arthrodesis unions have proved difficult to attain, but surgeons have noted clinical improvement in patients who developed fibrous unions at the scapholunate. ${ }^{86,87}$ One technique for scapholunate arthrodesis utilized a headless compression screw across the scapholunate joint. ${ }^{88}$ Herbert reported a higher scapholunate arthrodesis rate than other techniques but still found $30 \%$ of his patients develop a nonunion. ${ }^{85}$ With this knowledge, Rosenwasser et al developed the RASL procedure to stabilize the scapholunate joint with a Herbert screw, to allow for the growth of a durable soft tissue nonunion, or neoligament. ${ }^{89}$ Rosenwasser initially reported no cases of hardware failure or cut-out in the first 5 years of use of the technique. More recent follow-up reports good long-term results with an average Disabilities of the Arm Shoulder and Hand score of 17, SL angle of $55^{\circ}$, and SL diastasis of $2.1 \mathrm{~mm} .{ }^{90}$ Other studies have been less successful with the majority of patients having a recurrence of deformity or progression of arthritis. ${ }^{91}$

Modifications and combinations of tendon grafting and the RASL procedure have been attempted to combine the best aspects of each treatment. Fok and Fernandez report their technique of treating stage 4 SLL injuries with ECRL tendon reconstruction, SL screw fixation for protection of the reconstruction, and planned removal of the screw when loosening was noted on X-ray. They reported symptomatic relief in $95 \%$ of patients, SL angle of $56^{\circ}$, average SL gap of $2.5 \mathrm{~mm}$, average wrist flexion of $51^{\circ}$, average wrist extension of $55^{\circ}$, and $6 \%$ failure of procedure at an average follow-up of 7.9 years. $^{92}$

\section{Stage 5: chronic SLL injury with irreducible malalignment and normal joint cartilage}

In stage 5 SLL injuries, the ligament is irreparable, there is fixed, irreducible carpal malalignment, and the cartilage is normal. Arthroscopy will reveal fibrosis and deformation of the joint surfaces due to fixed malalignment, but no cartilage damage. Like stage 4 SLL injuries, these wrists exhibit static scapholunate dissociation. ${ }^{31}$ Plain radiographs will show fixed SL diastasis on the PA view and an increased SL angle on the lateral view. Irreducible malalignment means that the normal biomechanics of the wrist will never be restored. The best treatment options are those that provide some range of motion while eliminating pain. Various intercarpal arthrodesis have been described to reach this goal. As mentioned before, SL arthrodesis has been attempted but with limited success. There is very little surface area between the scaphoid and lunate, and significant physiologic loads, which makes it difficult for union to be achieved. Published union rates for scapholunate arthrodesis have been around 50\%. ${ }^{84,87,93}$ Scapholunate fibrous union may provide symptomatic relief after attempted scapholunate arthrodesis but there are limited long-term data. Scaphoid-trapezium-trapezoid (STT) arthrodesis has been used to restore radiocarpal congruency by correcting the position of the scaphoid in the radial scaphoid fossa. ${ }^{93,94}$ There is a higher rate of union with STT arthrodesis than SL arthrodesis with an $86 \%$ reported union rate. ${ }^{93}$ The procedure does result in decreased wrist range of motion and strength. Because the scaphoid can no longer flex, there is limited radial deviation and flexion for the wrist, and this may be painful. A radial styloidectomy has been added to the procedure by some surgeons to decrease radial impingement. ${ }^{95}$ Scaphoid-capitate (SC) arthrodesis has been shown to be an alternative and similar procedure to STT arthrodesis with one study reporting $87^{\circ}$ of wrist flexion-extension motion, $41^{\circ}$ of radio-ulnar deviation, $60 \%$ grip strength of the contralateral wrist, $90 \%$ return to work rate, and $30 \%$ rate of radiocarpal osteoarthritis at 10 years. ${ }^{96}$ The scaphoid-lunate-capitate arthrodesis was developed to correct the entire malalignment pattern but resulted in a significant loss of wrist motion $(50 \%) .{ }^{93}$ The radioscaphoidlunate fusion and distal scaphoidectomy were developed to restore the dart-thrower's plane of motion through the midcarpal joint at the expense of wrist flexion and extension. The midcarpal joint is preserved and the radiocarpal joint is fused to prevent the SLAC arthritis progression. Garcia-Elias et al added the excision of the distal third of the scaphoid to allow for more motion and decrease adjacent joint arthritis at the ST joint. ${ }^{97}$ Garcia-Elias et al reported on 16 patients who underwent this procedure and found pain relief for daily activities in $81 \%, 32^{\circ}$ of wrist flexion, $35^{\circ}$ of wrist extension, $14^{\circ}$ of radial deviation, and $19^{\circ}$ of ulnar deviation. Midcarpal arthritis developed in $12.5 \%$ of the patients at 37 months average follow-up. ${ }^{97}$ Limited intercarpal arthrodesis is recommended for patients with stage 5 SLL injuries who are seeking a reduction in their wrist pain and are willing to lose some but not all wrist range of motion. 


\section{Stage 6: chronic SLL injury with irreducible malalignment and cartilage damage}

In stage 6 SLL injuries, the ligament is irreparable, there is fixed, irreducible carpal malalignment, and the cartilage is damaged. Radiographs will show static scapholunate dissociation with arthritic changes at the wrist. These wrists are described as having SLAC. ${ }^{31}$ The patient may or may not have pain, and it is important to determine if any surgical treatment is necessary. A SLAC wrist is not always painful and may be an anatomic variant..$^{98-100}$ The treatments for SLAC wrist, often called salvage procedures, depend on the stage of arthritis as defined by Watson and Ballet. ${ }^{29}$ Stage 1 SLAC wrist exhibits radial styloid beaking, joint space narrowing, and sclerosis between the radial styloid and the distal pole of the scaphoid. Stage 2 SLAC wrist exhibits sclerosis and joint space narrowing throughout the radioscaphoid joint. Stage 3 SLAC wrist exhibits joint space narrowing and sclerosis between the lunate and capitate in addition to the changes seen in stages 1 and 2. A fourth stage has been added to include SLAC wrists with radiolunate arthritis. ${ }^{101}$ For wrists with arthritis between the radial styloid and the distal pole of the scaphoid, a radial styloidectomy can relieve pain that may occur with radial deviation of the wrist. ${ }^{29}$ The radial styloidectomy can be performed open or arthroscopically through the 1,2 portal. ${ }^{102}$ When performing a radial styloidectomy, it is important to protect the radiocarpal ligaments and avoid creating additional instability. ${ }^{2}$ The treatments for stage 2 SLAC wrist are intended to remove pressure from the arthritic cartilage of the distal radius scaphoid fossa. There are two options to do this: the proximal row carpectomy (PRC) or scaphoidectomy with midcarpal fusion. The PRC is performed by excising the proximal row carpal bones: the scaphoid, lunate, and triquetrum. A new joint is created between the capitate and the lunate fossa of the distal radius. Wall et al followed 16 patients for a minimum of 20 years and report that $35 \%$ required further surgery, the average flexion-extension arc was $68^{\circ}$, grip strength was $72 \%$ of the contralateral side, and all patients returned to work. ${ }^{103} \mathrm{~A}$ PRC is contraindicated in stage 3 SLAC wrist since an arthritic capitate would become the focal point of wrist loading. Scaphoidectomy with midcarpal fusion, often called the "four-corner arthrodesis", involves excision of the scaphoid and fusion of the capitate, hamate, lunate, and triquetrum. The four-corner arthrodesis can be used in stages 2 and 3 SLAC wrists. The arthrodesis can be performed with screws, staples, or procedure-specific plates. Bain and Watts followed 31 patients for a minimum of 10 years and report significant pain relief, additional surgery needed in $6 \%$, and no change in grip strength between 1 and 10 years after surgery. ${ }^{104}$ When there are arthritic changes at the radiolunate joint, the four-corner arthrodesis is contraindicated since the lunate facet of the radius will become the focal point of wrist loading. If there is pancarpal arthritis and the patient has significant pain, a total wrist arthrodesis can be beneficial. The procedure has been shown to provide significant pain relief in the majority of patients and improved grip strength, but lack of wrist range of motion must be discussed with the patient thoroughly prior to choosing this procedure. ${ }^{105,106}$ Arthroscopic techniques have also been developed for wrist arthrodesis with theoretical increased bone healing and range of motion due to less surgical exposure, which can result in scaring, decreased blood supply and damage to ligaments and capsular structures. ${ }^{107,108}$ Variations on wrist arthroplasty have also been described for the treatment of certain SLAC wrists. Midcarpal hemiarthroplasty for wrist arthritis has been shown at 4 years to improve wrist range of motion, grip strength, and patient-reported outcomes. ${ }^{109}$ In addition to the restorative surgical treatments for SLAC wrist, partial or total wrist denervation procedures are available. These procedures can be done alone or in addition to the salvage procedures. Rothe et al followed 46 patients for an average of 6.3 years after wrist denervation for chronic pain and found $32 \%$ were pain-free, $6 \%$ experienced no pain relief, and $9 \%$ required further surgery. ${ }^{110}$ There are good treatment options for patients with all stages of SLAC wrist, but none are perfect. Careful surgical candidate selection and thorough preoperative discussion can help guide patient expectations and outcome.

\section{Conclusions}

SLL injuries can be difficult to identify and manage. There are treatments available for the full spectrum of SLL injuries from acute injury to chronic SLAC. Careful clinical suspicion and appropriate management may prevent chronic pain and wrist dysfunction, but more long-term studies with larger patient numbers need to be performed. The optimal management of SLL injuries is yet to be determined.

\section{Disclosure}

The authors report no conflicts of interest in this work.

\section{References}

1. Feipel V, Rooze M. The capsular ligaments of the wrist: morphology, morphometry and clinical applications. Surg Radiol Anat. 1999;21(3):175-180.

2. Berger RA. The ligaments of the wrist. A current overview of anatomy with considerations of their potential functions. Hand Clin. 1997;13(1):63-82. 
3. Moojen TM, Snel JG, Ritt MJPF, Venema HW, Kauer JMG, Bos KE. In vivo analysis of carpal kinematics and comparative review of the literature. J Hand Surg Am. 2003;28(1):81-87.

4. Gupta A. Factors affecting the sagittal alignment of the lunate. J Hand Surg Eur Vol. 2007;32(2):155-159.

5. Ishikawa J, Cooney WP, Niebur G, An KN, Minami A, Kaneda K. The effects of wrist distraction on carpal kinematics. J Hand Surg Am. 1999;24(1):113-120.

6. Brigstocke GHO, Hearnden A, Holt C, Whatling G. In-vivo confirmation of the use of the dart thrower's motion during activities of daily living. J Hand Surg Eur Vol. 2014;39(4):373-378.

7. Crisco JJ, Heard WMR, Rich RR, Paller DJ, Wolfe SW. The mechanical axes of the wrist are oriented obliquely to the anatomical axes. J Bone Joint Surg Am. 2011;93(2):169-177.

8. Majima M, Horii E, Matsuki H, Hirata H, Genda E. Load transmission through the wrist in the extended position. J Hand Surg Am. 2008;33(2):182-188.

9. Viegas SF, Patterson RM, Todd PD, McCarty P. Load mechanics of the midcarpal joint. J Hand Surg Am. 1993;18(1):14-18.

10. Short WH, Werner FW, Green JK, Masaoka S. Biomechanical evaluation of ligamentous stabilizers of the scaphoid and lunate. $J$ Hand Surg. 2002;27(6):991-1002.

11. Elsaidi GA, Ruch DS, Kuzma GR, Smith BP. Dorsal wrist ligament insertions stabilize the scapholunate interval: cadaver study. Clin Orthop Relat Res. 2004;(425):152-157.

12. Mitsuyasu H, Patterson RM, Shah MA, Buford WL, Iwamoto Y, Viegas SF. The role of the dorsal intercarpal ligament in dynamic and static scapholunate instability. J Hand Surg Am. 2004;29(2): 279-288.

13. Tommasini Carrara de Sambuy M, Burgess TM, Cambon-Binder A, Mathoulin CL. The anatomy of the dorsal capsulo-scapholunate septum: a cadaveric study. J Wrist Surg. 2017;6(3):244-247.

14. Overstraeten LV, Camus EJ, Wahegaonkar A, et al. Anatomical description of the dorsal capsulo-scapholunate septum (DCSS)-arthroscopic staging of scapholunate instability after DCSS sectioning. $J$ Wrist Surg. 2013;2(2):149-154.

15. Van Overstraeten L, Camus EJ. Arthroscopic classification of the lesions of the dorsal capsulo-scapholunate septum (DCSS) of the wrist. Tech Hand Up Extrem Surg. 2016;20(3):125-128.

16. Esplugas M, Garcia-Elias M, Lluch A, Llusá-Pérez M. Role of muscles in the stabilization of ligament-deficient wrists. J Hand Ther. 2016;29(2):166-174.

17. Salva-Coll G, Garcia-Elias M, Llusa-Perez M, Rodríguez-Baeza A. The role of the flexor carpi radialis muscle in scapholunate instability. $J$ Hand Surg. 2011;36(1):31-36.

18. Salva-Coll G, Garcia-Elias M, Leon-Lopez MT, Llusa-Perez M, Rodríguez-Baeza A. Effects of forearm muscles on carpal stability. J Hand Surg Eur Vol. 2011;36(7):553-559.

19. Hagert E, Ljung B-O, Forsgren S. General innervation pattern and sensory corpuscles in the scapholunate interosseous ligament. Cells Tissues Organs. 2004;177(1):47-54.

20. Hagert E, Persson JKE, Werner M, Ljung B-O. Evidence of wrist proprioceptive reflexes elicited after stimulation of the scapholunate interosseous ligament. J Hand Surg. 2009;34(4):642-651.

21. Hagert E. Proprioception of the wrist joint: a review of current concepts and possible implications on the rehabilitation of the wrist. $J$ Hand Ther. 2010;23(1):2-16.

22. Salvà-Coll G, Garcia-Elias M, Hagert E. Scapholunate instability: proprioception and neuromuscular control. J Wrist Surg. 2013;2(2):136-140.

23. Berger RA, Imeada T, Berglund L, An KN. Constraint and material properties of the subregions of the scapholunate interosseous ligament. J Hand Surg Am. 1999;24(5):953-962.

24. Linscheid RL, Dobyns JH, Beabout JW, Bryan RS. Traumatic instability of the wrist. Diagnosis, classification, and pathomechanics. J Bone Joint Surg Am. 1972;54(8):1612-1632.
25. Lal H, Tanwar YS, Jaiswal A, Singh SP, Habib M. Scapulothoracic and scapholunate dissociation in the ipsilateral upper limb of a trauma victim. Chin J Traumatol. 2014;17(4):242-245.

26. Kitay A, Wolfe SW. Scapholunate instability: current concepts in diagnosis and management. J Hand Surg Am. 2012;37(10):2175-2196.

27. Gunal I, Ozaksoy D, Altay T, Satoglu IS, Kazimoglu C, Sener M. Scapholunate dissociation associated with distal radius fractures. Eur J Orthop Surg Traumatol. 2013;23(8):877-881.

28. Mayfield JK, Johnson RP, Kilcoyne RK. Carpal dislocations: pathomechanics and progressive perilunar instability. J Hand Surg Am. 1980;5(3):226-241.

29. Watson HK, Ballet FL. The SLAC wrist: scapholunate advanced collapse pattern of degenerative arthritis. J Hand Surg Am. 1984;9(3): 358-365.

30. Trehan SK, Lee SK, Wolfe SW. Scapholunate advanced collapse: nomenclature and differential diagnosis. J Hand Surg. 2015;40(10): 2085-2089.

31. Watson H, Ottoni L, Pitts EC, Handal AG. Rotary subluxation of the scaphoid: a spectrum of instability. J Hand Surg Br. 1993;18(1):62-64.

32. Gillig JD, White SD, Rachel JN. Acute carpal tunnel syndrome: a review of current literature. Orthop Clin North Am. 2016;47(3):599-607.

33. Linn MR, Mann FA, Gilula LA. Imaging the symptomatic wrist. Orthop Clin North Am. 1990;21(3):515-543.

34. Sulkers GSI, Schep NWL, Maas M, van der Horst CMAM, Goslings JC, Strackee SD. The diagnostic accuracy of wrist cineradiography in diagnosing scapholunate dissociation. J Hand Surg Eur Vol. 2014;39(3):263-271.

35. Kuo CE, Wolfe SW. Scapholunate instability: current concepts in diagnosis and management. J Hand Surg. 2008;33(6):998-1013.

36. Dobyns JH, Linscheid RL. A short history of the wrist joint. Hand Clin. 1997;13(1):1-12.

37. Meister DW, Hearns KA, Carlson MG. Dorsal scaphoid subluxation on sagittal magnetic resonance imaging as a marker for scapholunate ligament tear. J Hand Surg. 2017;42(9):717-721.

38. Ringler MD. MRI of wrist ligaments. J Hand Surg. 2013;38(10): 2034-2046.

39. Nagle D, Benson L. Wrist arthroscopy: indications and results. Arthroscopy. 1992;8(2):198-203.

40. Bain G, Munt J, Turner P. New advances in wrist arthroscopy. Arthroscopy. 2008;24(3):355-367.

41. Gupta R, Bozentka DJ, Osterman AL. Wrist arthroscopy: principles and clinical applications. J Am Acad Orthop Surg. 2001;9(3):200-209.

42. Geissler WB, Freeland AE, Savoie FH, McIntyre LW, Whipple TL. Intracarpal soft-tissue lesions associated with an intra-articular fracture of the distal end of the radius. J Bone Joint Surg Am. 1996;78(3):357-365.

43. Dreant N, Dautel G. Development of a arthroscopic severity score for scapholunate instability. Chir Main. 2003;22(2):90-94.

44. Dreant N, Mathoulin C, Lucchetti R, Pegoli L. Comparison of two arthroscopic classifications for scapholunate instability. Chir Main. 2009;28(2):74-77.

45. Messina JC, Van Overstraeten L, Luchetti R, Fairplay T, Mathoulin CL. The EWAS Classification of scapholunate tears: an anatomical arthroscopic study. J Wrist Surg. 2013;2(2):105-109.

46. Corella F, Del Cerro M, Ocampos M, Larrainzar-Garijo R. The "rocking chair sign" for floating lunate. J Hand Surg. 2015;40(11):2318-2319.

47. Corella F, Ocampos M, Cerro MD. Arthroscopic scaphoid 3D test for scapholunate instability. J Wrist Surg. 2018;7(1):89-92.

48. Garcia-Elias M, Lluch AL, Stanley JK. Three-ligament tenodesis for the treatment of scapholunate dissociation: indications and surgical technique. J Hand Surg Am. 2006;31(1):125-134.

49. Weiss AP, Sachar K, Glowacki KA. Arthroscopic debridement alone for intercarpal ligament tears. J Hand Surg Am. 1997;22(2):344-349.

50. Ruch DS, Poehling GG. Arthroscopic management of partial scapholunate and lunotriquetral injuries of the wrist. J Hand Surg Am. 1996;21(3):412-417. 
51. Darlis NA, Weiser RW, Sotereanos DG. Partial scapholunate ligament injuries treated with arthroscopic debridement and thermal shrinkage. J Hand Surg Am. 2005;30(5):908-914.

52. Manuel J, Moran SL. The diagnosis and treatment of scapholunate instability-sciencedirect. Hand Clin. 2010;26(1):129-144.

53. Beredjiklian PK, Dugas J, Gerwin M. Primary repair of the scapholunate ligament. Tech Hand Up Extrem Surg. 1998;2(4):269-273.

54. Bickert B, Sauerbier M, Germann G. Scapholunate ligament repair using the Mitek bone anchor. J Hand Surg Br. 2000;25(2):188-192.

55. Andersson JK, Garcia-Elias M. Dorsal scapholunate ligament injury: a classification of clinical forms. J Hand Surg Eur Vol. 2013;38(2):165-169.

56. Berger RA, Bishop AT, Bettinger PC. New dorsal capsulotomy for the surgical exposure of the wrist. Ann Plast Surg. 1995;35(1):54-59.

57. Rosati M, Parchi P, Cacianti M, Poggetti A, Lisanti M. Treatment of acute scapholunate ligament injuries with bone anchor. Musculoskelet Surg. 2010;94(1):25-32.

58. Mathoulin C, Messina J. Treatment of acute scapholunate ligament tears with simple wiring and arthroscopic assistance. Chir Main. 2010;29(2):72-77.

59. Carratalá V, Lucas FJ, Miranda I, Sánchez Alepuz E, González Jofré C. Arthroscopic scapholunate capsuloligamentous repair: suture with dorsal capsular reinforcement for scapholunate ligament lesion. Arthrosc Tech. 2017;6(1):e113-e120.

60. Del Piñal F. Arthroscopic volar capsuloligamentous repair. J Wrist Surg. 2013;2(2):126-128.

61. Rohman EM, Agel J, Putnam MD, Adams JE. Scapholunate interosseous ligament injuries: a retrospective review of treatment and outcomes in 82 wrists. J Hand Surg. 2014;39(10):2020-2026.

62. Camus EJ, Van Overstraeten L. Dorsal scapholunate stabilization using Viegas' capsulodesis: 25 cases with 26 months-follow-up. Chir Main. 2013;32(6):393-402.

63. Gajendran VK, Peterson B, Slater RR, Szabo RM. Long-term outcomes of dorsal intercarpal ligament capsulodesis for chronic scapholunate dissociation. J Hand Surg Am. 2007;32(9):1323-1333.

64. Harvey EJ, Berger RA, Osterman AL, Fernandez DL, Weiss A-P. Bone-tissue-bone repairs for scapholunate dissociation. J Hand Surg Am. 2007;32(2):256-264.

65. Megerle K, Bertel D, Germann G, Lehnhardt M, Hellmich S. Longterm results of dorsal intercarpal ligament capsulodesis for the treatment of chronic scapholunate instability. J Bone Joint Surg Br. 2012;94(12):1660-1665.

66. Szabo RM, Slater RR Jr, Palumbo CF, Gerlach T. Dorsal intercarpal ligament capsulodesis for chronic, static scapholunate dissociation: clinical results. J Hand Surg. 2002;27(6):978-984.

67. Moran SL, Cooney WP, Berger RA, Strickland J. Capsulodesis for the treatment of chronic scapholunate instability. J Hand Surg. 2005;30(1):16-23.

68. Deshmukh SC, Givissis P, Belloso D, Stanley JK, Trail IA. Blatt's capsulodesis for chronic scapholunate dissociation. J Hand Surg Br. 1999;24(2):215-220.

69. MD KM, MD DB, Marcus Lehnhardt MD P, Guenter Germann MD P, MD SH. Long-term follow-up of modified Blatt's capsulodesis for the treatment of scapholunate ligament injuries. J Hand Surg Am. 2011;36(8):52.

70. Moran SL, Ford KS, Wulf CA, Cooney WP. Outcomes of dorsal capsulodesis and tenodesis for treatment of scapholunate instability. J Hand Surg Am. 2006;31(9):1438-1446.

71. Soong M, Merrell GA, Ortmann F, Weiss APC. Long-term results of bone-retinaculum-bone autograft for scapholunate instability. J Hand Surg Am.2013;38(3):504-508.

72. Seradge H, Baer C, Dalsimer D, Seradge A, Shafi RAR, Parker W. Treatment of dynamic scaphoid instability. JTrauma. 2004;56(6):1253-1260.

73. Rosenwasser M, Miyasajsa K, Strauch R. The RASL procedure: reduction and association of the scaphoid and lunate using the Herbert screw. Tech Hand Up Extrem Surg. 1997;1(4):263.
74. Brunelli G-A, Brunelli G-A. Carpal instability with scapho-lunate dissociation treated using the flexor carpi radialis and scaphoid-trapezoid ligament repair: foundations, technique and results of preliminary series. Rev Chir Orthop Reparatrice Appar Mot. 2003;89(2):152-157.

75. Ross M, Loveridge J, Cutbush K, Couzens G. Scapholunate ligament reconstruction. J Wrist Surg. 2013;2(2):110-115.

76. De Smet L, Goeminne S, Degreef I. Failures of the three-ligament tenodesis for chronic static scapholunate dissociation are due to insufficient reduction. Acta Orthop Bel. 2011;77(5):595-597.

77. Taleisnik J. Current concepts review. Carpal instability. J Bone Joint Surg Am. 1988;70(8):1262-1268.

78. Chee KG, Chin AYH, Chew EM, Garcia-Elias M. Antipronation spiral tenodesis-a surgical technique for the treatment of perilunate instability. J Hand Surg. 2012;37(12):2611-2618.

79. Corella F, Del Cerro M, Ocampos M, Larrainzar-Garijo R. Arthroscopic ligamentoplasty of the dorsal and volar portions of the scapholunate ligament. J Hand Surg. 2013;38(12):2466-2477.

80. Corella F, Del Cerro M, Ocampos M, Simon de Blas C, LarrainzarGarijo R. Arthroscopic scapholunate ligament reconstruction, volar and dorsal reconstruction. Hand Clin. 2017;33(4):687-707.

81. Carratalá V, Lucas FJ, Alepuz ES, Guisasola E, Calero R. Arthroscopically assisted ligamentoplasty for axial and dorsal reconstruction of the scapholunate ligament. Arthrosc Tech. 2016;5(2):e353-e359.

82. Ho P-C, Wong CW-Y, Tse WL. Arthroscopic-assisted combined dorsal and volar scapholunate ligament reconstruction with tendon graft for chronic SL instability. J Wrist Surg. 2015;4(4):252-263.

83. Faithfull DK, Herbert TJ. Small joint fusions of the hand using the Herbert Bone Screw. J Hand Surg Br. 1984;9(2):167-168.

84. Hastings DE, Silver RL. Intercarpal arthrodesis in the management of chronic carpal instability after trauma. J Hand Surg Am. 1984;9(6): 834-840.

85. Herbert TJ. Use of the Herbert bone screw in surgery of the wrist. Clin Orthop Relat Res. 1986;(202):79-92.

86. Russell TB. Inter-carpal dislocations and fracture-dislocations; a review of 59 cases. J Bone Joint Surg Br. 1949;31B(4):524-531.

87. Hom S, Ruby LK. Attempted scapholunate arthrodesis for chronic scapholunate dissociation. J Hand Surg Am. 1991;16(2):334-339.

88. Herbert TJ. Internal fixation of the carpus with the Herbert bone screw system. J Hand Surg Am. 1989;14(2 Pt 2):397-400.

89. Rosenwasser MP, Paul SB, Froimson AI. Arthroplasty of the hand and wrist. Hand Clin. 1989;5(3):487-505.

90. White NJ, Raskolnikov D, Crow SA, Swart E, Rosenwasser MP. Reduction and association of the scaphoid and lunate (RASL): longterm follow-up of a reconstruction technique for chronic scapholunate dissociation. J Hand Surg Am. 2017;35(10):16-17.

91. Larson TB, Stern PJ. Reduction and association of the scaphoid and lunate procedure: short-term clinical and radiographic outcomes. J Hand Surg. 2014;39(11):2168-2174.

92. Fok MWM, Fernandez DL. Chronic scapholunate instability treated with temporary screw fixation. J Hand Surg. 2015;40(4): $752-758$.

93. Stewart DT, Froelich JM, Shin AY. Intercarpal arthrodeses. J Hand Surg. 2014;39(2):373-377.

94. Watson HK, Weinzweig J, Zeppieri J. The natural progression of scaphoid instability. Hand Clin. 1997;13(1):39-49.

95. Bain GI, McGuire DT. Decision making for partial carpal fusions. $J$ Wrist Surg. 2012;1(2):103-114.

96. Luegmair M, Saffar P. Scaphocapitate arthrodesis for treatment of scapholunate instability in manual workers. J Hand Surg Am. 2013;38(5):878-886.

97. Garcia-Elias M, Lluch A, Ferreres A, Papini-Zorli I, Rahimtoola ZO. Treatment of radiocarpal degenerative osteoarthritis by radioscapholunate arthrodesis and distal scaphoidectomy. J Hand Surg Am. 2005;30(1):8-15.

98. Fassler PR, Stern PJ, Kiefhaber TR. Asymptomatic SLAC wrist: does it exist? J Hand Surg Am. 1993;18(4):682-686. 
99. Gharbaoui IS, Netscher DT, Kessler FB. Chronic asymptomatic contralateral wrist scapholunate dissociation. Plast Reconstr Surg. 2005;116(6):1672-1678.

100. Vance RM, Gelberman RH, Braun RM. Chronic bilateral scapholunate dissociation without symptoms. J Hand Surg Am . 1979;4(2):178-180.

101. Weiss KE, Rodner CM. Osteoarthritis of the wrist. J Hand Surg. 2007;32(5):725-746.

102. Yao J, Osterman AL. Arthroscopic techniques for wrist arthritis (radial styloidectomy and proximal pole hamate excisions). Hand Clin. 2005;21(4):519-526.

103. Wall LB, Didonna ML, Kiefhaber TR, Stern PJ. Proximal row carpectomy: minimum 20-year follow-up. J Hand Surg. 2013;38(8):1498-1504.

104. Bain GI, Watts AC. The outcome of scaphoid excision and four-corner arthrodesis for advanced carpal collapse at a minimum of ten years. J Hand Surg. 2010;35(5):719-725.
105. Rauhaniemi J, Tiusanen H, Sipola E. Total wrist fusion: a study of 115 patients. J Hand Surg Br. 2005;30(2):217-219.

106. Adey L, Ring D, Jupiter JB. Health status after total wrist arthrodesis for posttraumatic arthritis. J Hand Surg Am. 2005;30(5):932-936.

107. Baur E-M. Arthroscopic-assisted partial wrist arthrodesis. Hand Clin. 2017;33(4):735-753.

108. del Piñal F, Tandioy-Delgado F. (Dry) arthroscopic partial wrist arthrodesis: tips and tricks. Handchir Mikrochir Plast Chir. 2014;46(5):300-306.

109. Anneberg M, Packer G, Crisco JJ, Wolfe S. Four-year outcomes of midcarpal hemiarthroplasty for wrist arthritis. J Hand Surg. 2017;42(11): 894-903.

110. Rothe M, Rudolf K-D, Partecke B-D. Long-term results following denervation of the wrist in patients with stages II and III SLAC-/ SNAC-wrist. Handchir Mikrochir Plast Chir. 2006;38(4):261-266.
Orthopedic Research and Reviews

\section{Publish your work in this journal}

Orthopedic Research and Reviews is an international, peer-reviewed, open access journal that focusing on the patho-physiology of the musculoskeletal system, trauma, surgery and other corrective interventions to restore mobility and function. Advances in new technologies, materials, techniques and pharmacological agents are particularly

\section{Dovepress}

welcome. The manuscript management system is completely online and includes a very quick and fair peer-review system, which is all easy to use. Visit http://www.dovepress.com/testimonials.php to read real quotes from published authors.

Submit your manuscript here: https://www.dovepress.com/orthopedic-research-and-reviews-journal 